\title{
Effect of fibre orientation on the mechanical properties of polypropylene-lyocell composites
}

\author{
Michael Cordin (D) Thomas Bechtold • Tung Pham
}

Received: 24 May 2018/Accepted: 4 October 2018/Published online: 11 October 2018

(C) The Author(s) 2018

\begin{abstract}
Natural fibre reinforced plant structures are widely used in nature. These plant structures combine light weight with superior mechanical properties. The fibre orientations in plants are optimized to the occurring forces, especially to the bending of plants by wind forces. Therefore it is important to study the effect of fibre orientation to the mechanical properties of materials in a systematic experimental approach. In this study the effect of reinforcement fibre orientation on mechanical properties of biobased lyocell-reinforced polypropylene composite was analysed. For this purpose, special technique to produce composites with defined fibre orientation and fibre wetting was developed consisting of the production of intermingled hybrid yarn followed by defined
\end{abstract}

yarn laying and thermoforming processes. The formed composites were subjected to tensile strength tests and dynamic mechanical analyses. The experimentally determined E-modulus was compared with values, calculated from the modified rule of mixture of Virk and Krenchel. The analysis showed that the experimental E-moduli were somewhat smaller than the theoretical values, which is indicative of a less than perfect interfacial bonding between the fibres and matrix. The influence of water on the composite performance was also analysed. It was shown that the composites sorb approximately $30 \%$ water by weight, and it has a strong influence on the E-modulus and other performance parameters. eu. 


\section{Graphical abstract}

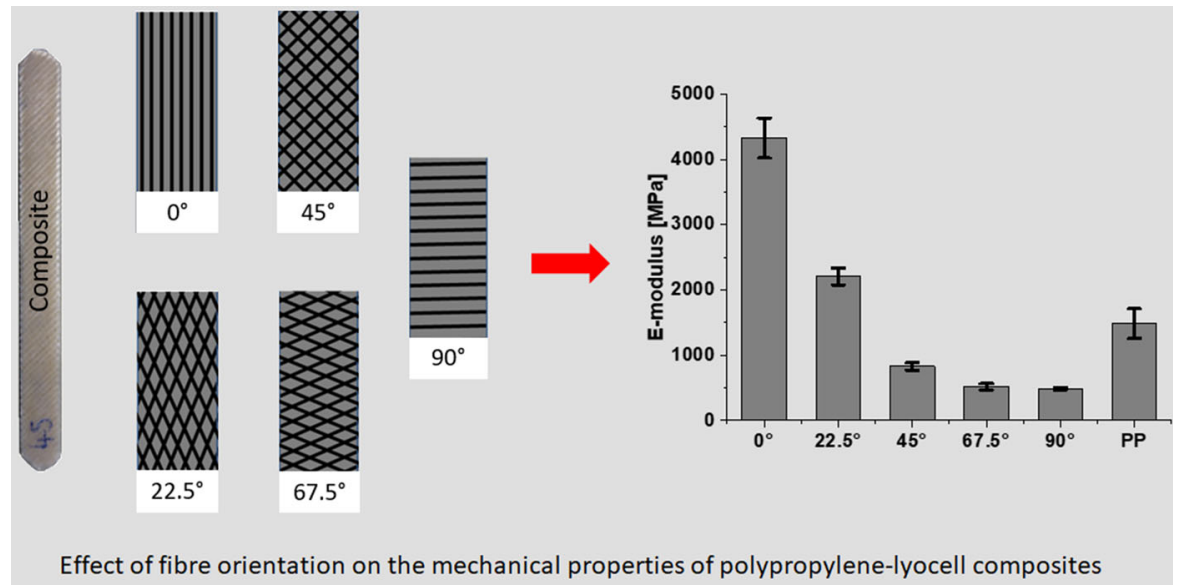

Keywords Polymer-matrix composites - Lyocell · Polypropylene $\cdot$ Fibre orientation $\cdot$ E-modulus

\section{Introduction}

Nature uses the concept of optimised reinforcing fibre orientation to produce plant structures to withstand natural forces, such as the bending of plants by wind power. This concept was the inspiration to design similar man made composites and to study the effect of fibre orientation in a systematic experimental investigation. In general, fibre-reinforced plastics show enhanced properties such as low weight, corrosion resistance, and high tensile strength and modulus. In technical applications the use of carbon, glass and aramid-fibres as reinforcement in matrix-polymers is common (Spoljaric et al. 2009). But these fibres have disadvantages such as high production costs, difficulties in their recycling and their end of life (Shanks et al. 2004). Therefore the use of natural and regenerated cellulose fibres to reinforce matrix polymers has generated much interest in recent years. Especially cellulose type polymers, for example rayon and lyocell (CLY) are able to substitute conventional inorganic reinforcing materials. The advantages of natural and regenerated fibres over conventional inorganic fibres are for example economic viability, low tool wear, reduced dust formation, reduced dermal irritation and biodegradability (Bledzki and Gassan 1999; Wambua et al. 2003). Natural and regenerated fibre reinforced polymer composites also have some disadvantages such as the low adhesion between the hydrophilic natural fibres and the hydrophobic polymer matrix (Bledzki and Gassan 1999). In the literature, physical and chemical surface treatments of the reinforcing natural fibres are described to improve the adhesion between fibres and matrix (Belgacem et al. 2003; Gray 2008; Joly et al. 1996; Qiu et al. 2003; Quan et al. 2005; Quillin et al. 1992, 1993). For example the hydrophilicity of polypropylene (PP) can be increased by modification with maleic anhydride, resulting in an improved adhesion between the matrix polymer and natural fibres (Bataille et al. 1989; Joseph et al. 2003; Khalid et al. 2006; Shubhra et al. 2011; Spoljaric et al. 2009; Qiu et al. 2005, 2006). The preparation and characterization of composites, consisting of PP matrix and cellulose (Amash and Zugenmaier 1998, 2000; Bengtsson et al. 2007; Ganster et al. 2006; Kuboki 2014; Zugenmaier 2006) or cellulosebased plant fibres like bagasse (Ashori and Nourbakhsh 2009), jute (Acha et al. 2007; Doan et al. 2006, 2007; Gassan and Bledzki 1997; Karmaker and Youngquist 1996; Rahman et al. 2010), hemp (Niu et al. 2011) and sisal (Joseph et al. 2003) have already been reported in the literature. These composites suffer from the problem of moisture absorption in the presence of humid air or when immersed in water (Espert et al. 2004). The absorbed water accumulates at the interface of fibres and matrix and induces debonding. Thus, the propensity for stress transfer between the matrix and fibre is reduced, which results in a reduction of mechanical properties. The negative 
influence of water sorption can be reduced by the use of coupling agents and special fibre treatments. Composites prepared from thermoset matrix suffer from the problem of difficult processing after curing. It would consequently be desirable to replace thermosetting by thermoplastic matrix materials. The use of thermoplastic polymers combined with natural or regenerated fibres, like CLY allows the efficient mass production of composites. During the last decade, many efforts are made in order to generate thermoplastic composites reinforced with man-made fibres with special emphasis on fibre orientation in the composites. Starting with a wet-lay process which is similar to papermaking (Johnson et al. 2008), reported on the mechanical properties of PP/cellulose fibre composites with random oriented fibres. By employing typical thermoplastic compounding technology such as extrusion process, PP/CLY compounds were prepared (Mirza et al. 2009, 2010; Borja et al. 2005; Ganster et al. 2008; Huque et al. 2012; Paunikallio et al. 2003a, b; Abdennadher et al. 2016; Zarges et al. 2017) in order to get good distribution of the cellulose fibres in the PP matrix. However, only chopped fibres were suitable for compounding technologies and the fibre orientation cannot be influenced, especially when conversion techniques such as compression moulding (Mirza et al. 2009, 2010; Huque et al. 2012) or injection moulding (Paunikallio et al. 2003a, b, Abdennadher et al. 2016; Zarges et al. 2017) were used to produce sample specimens after the compounding step. In case of compression moulding the chopped fibres are oriented randomly in the press mould. When injection moulding technique was used, the chopped fibres will be forced to align predominantly along the flow channel during the mould filling process. In both cases, there was no control on the fibre orientation possible. Other research groups have developed pultrusion technique to produce continuous coated cellulose tows (Ganster and Fink 2006; Ganster et al. 2006; Feldmann 2016). The coated tows, however, were pelletised for further conversion step such as injection moulding. The developed pultrusion techniques allowed a good fibre wetting and distribution of the matrix polymers. However, during the pelletising step, the fibres were cut and no orientation control of the chopped fibres could be done during the part shaping process.

In the recent work, we followed the approach of a reinforcing textile structure, allowing the preparation of composites with special fibre orientations. This allows the design of composites with improved mechanical properties along specific directions to support angular loads encountered in the end use applications. The stiffness of a composite as function of composition, fibre orientation (Krenchel 1964) and other fibre parameters can be predicted by the so called modified rule of mixture, according to Virk and Cullen (Virk et al. 2012; Cullen et al. 2013). This rule suggests a strong orientation dependence of the composite stiffness, showing clearly the importance of an accurate design of the composite with respect to the fibre orientation and the expected load directions. The effect of fibre orientation on the mechanical properties of a composite has received already attention in the literature (Hussain et al. 2013; Adams and Bacon 1973; Jackson and Cratchley 1966; Madhuri et al. 2017).

In order to combine good fibre wetting and defined orientation of long and continuous fibres, respectively, following strategy was followed in the present study. In the first step, CLY fibres are included into intermingled hybrid yarn, which consists of PP fibres and CLY fibres with the weight ratio of 50:50. This step led to a very good distribution of CLY fibres and PP fibres allowing a perfect wetting of CLY fibres. In the next processing sequence the hybrid yarn is layered in the desired orientation on a PP fleece followed by a hot press process above the melting point of PP to generate preforms for the later preparation of the final composites. The concept to use intermingled hybrid yarn improves the wetting of fibres by molten PP material during the thermoforming process and thus enhances mechanical properties of composites, which are prepared in such a way.

\section{Experimental}

Materials and sample preparation

For the preparation of composites, polypropylenelyocell hybrid yarn from Schoeller GmbH \& CoKG (Hard, Austria) was used. In previous work, the fibre fineness for the polypropylene (PP) and the cellulose type lyocell fibres (CLY) were determined, which was 3.2 dtex $(\varnothing=20,6 \mu \mathrm{m})$ and $3.4 \mathrm{dtex}(\varnothing=17,0 \mu \mathrm{m})$, respectively (Cordin et al. 2017). The fibre fineness of single PP and CLY fibres was determined with the 
help of the Vibroscop and Vibrodyn testing machines (Lenzing Technik, Lenzing, Austria). The staple length of the fibres in the hybrid yarn was between 105 and $120 \mathrm{~mm}$. According to Woodings (2001) the E-modulus of dry lyocell is $24 \mathrm{GPa}$ and that of wet lyocell is $5.7 \mathrm{GPa}$.

Five different types of composites were prepared with different orientation angle of the reinforcing CLY fibres to the long axis: $0^{\circ}, \pm 22.5^{\circ}, \pm 45^{\circ}, \pm 67.5^{\circ}$ and $90^{\circ}$ fibre orientation were characterized (see Fig. 1). The final material composition was kept constant and consisted 62\% w/w PP and 38\% w/w lyocell fibres. The starting preform for the composite preparation was a PP fleece, reinforced with hybrid yarn at the desired angle. The final composite was then prepared by thermoforming of four such layers under a pressure of 50 bar and a temperature of $180{ }^{\circ} \mathrm{C}$. The four layers have alternate fibre orientation in the + and - direction. The thermoforming was performed with a heatable press (Polystat $200 \mathrm{~T}$, Servitec $\mathrm{GmbH}$, Wustermark, Germany). The prepared composites were rectangular in shape, with a length of $100 \mathrm{~mm}$, a width of $10 \mathrm{~mm}$ and a thickness of $1 \mathrm{~mm}$ (the dimensions of the composites were determined with a calliper).

\section{Analytical methods}

Tensile properties were determined using a tensile testing machine (Zwick Roell Z250, Ulm, Germany). The composites used for the tensile test experiments have a rectangular shape with a length of $100 \mathrm{~mm}$, a width of $10 \mathrm{~mm}$ and a thickness of $1 \mathrm{~mm}$. The gauge length of the clamped composites was $30 \mathrm{~mm}$. The tensile test was performed at a speed of $10 \mathrm{~mm} / \mathrm{min}$.
The elongation was determined from the cross-head movement of the tensile test device. The elastic modulus, ultimate tensile strength and strain at ultimate tensile strength were calculated from the experimentally determined stress-strain curves. The values reported here are the average of five samples. Besides, the standard deviation was calculated and is shown as error bars in the respective figures.

The tensile tests were performed both in the dry and wet states of the composite. The wet composites were prepared by submerging the samples in water at room temperature. During specific time periods, composites were removed from the water bath and then the surface of the wet composites was dried by wiping with an absorbent paper towel. The water content of the composite was determined by weighing. Mechanical tensile properties were characterised for composites, which absorbed water during a time period of $195 \mathrm{~h}$.

Optical micrographs of composite samples were taken using an Olympus SZX16 microscope (Tokyo, Japan). Images were captured with an Olympus XC50 digital camera (Tokyo, Japan). The $\mu \mathrm{CT}$ images were obtained using a high resolution computed tomography system (phoenix nanotom m, GE, USA).

Composites in the dry as well as in wet states were also characterised by dynamic mechanical thermal analysis (DMTA in torsion). These experiments were performed with the rheometer MCR302 (Anton-Paar $\mathrm{GmbH}$, Graz, Austria). From these experiments, the storage and loss modulus were determined during a frequency sweep and during a temperature ramp. The DMTA measurement was performed with an oscillation frequency of $1 \mathrm{~Hz}$, a shear deformation of $0.01 \%$ and a temperature ramp of $2{ }^{\circ} \mathrm{C} / \mathrm{min}$. The clamping length was $26 \mathrm{~mm}$.
Fig. 1 Schematic illustration of the composites with different fibre orientation

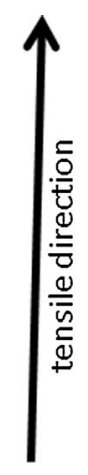

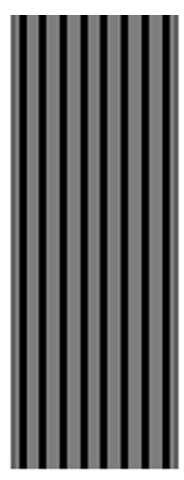

$0^{\circ}$

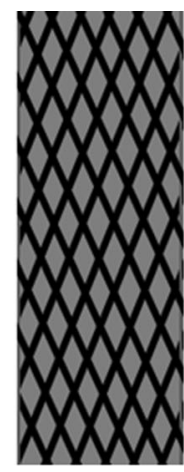

$\pm 22.5^{\circ}$

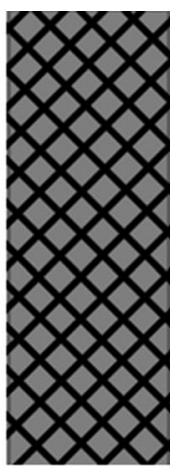

$\pm 45^{\circ}$

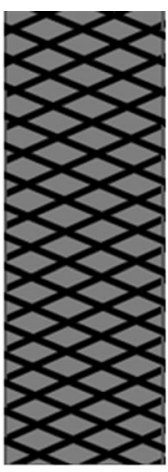

$\pm 67.5^{\circ}$

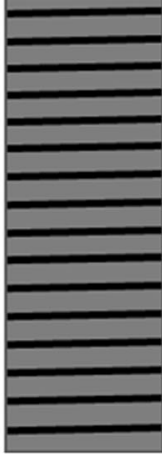

$90^{\circ}$ 


\section{Results and discussion}

In the prepared composites the CLY fibres are the reinforcement and the isotactic PP forms the matrix, which connects the reinforcing fibres and gives it its form. By special alignment of the hybrid yarn in the composite preform, it is possible to get composites with special oriented reinforcement. The mixing and distribution of CLY and PP fibres were already done during the preparation of the hybrid yarn, which improves the interface between the two materials during the thermoforming and prevents undesirable agglomeration of CLY fibres. It is known, that the binding between PP and CLY is not optimal due to the different polarity of the two materials. The strategy, used in this study to improve the wetting and interface interaction between CLY and PP is to employ the hybrid yarn concept. The very small diameter of the used CLY fibres (fibre fineness 3.4 dtex) in combination with a large fibre length $(\geq 105 \mathrm{~mm})$ improves the reinforcing effect by favouring the load transmission between fibres and matrix. It was shown in a previous work that this concept leads to composites with excellent mechanical properties (Cordin et al. 2017). In continuation of this work, the influence of the reinforcing fibre orientation was now studied. The ultimate tensile strength dependence on the fibre orientation is shown in Fig. 2a. The highest ultimate tensile strength (UTS) of $147 \mathrm{MPa}$ was observed for the composite with all CLY fibres oriented parallel to the direction, in which the tensile force was applied in the tensile test experiment. The UTS of pure PP is $50.4 \mathrm{MPa}$. By changing the fibre orientation angle

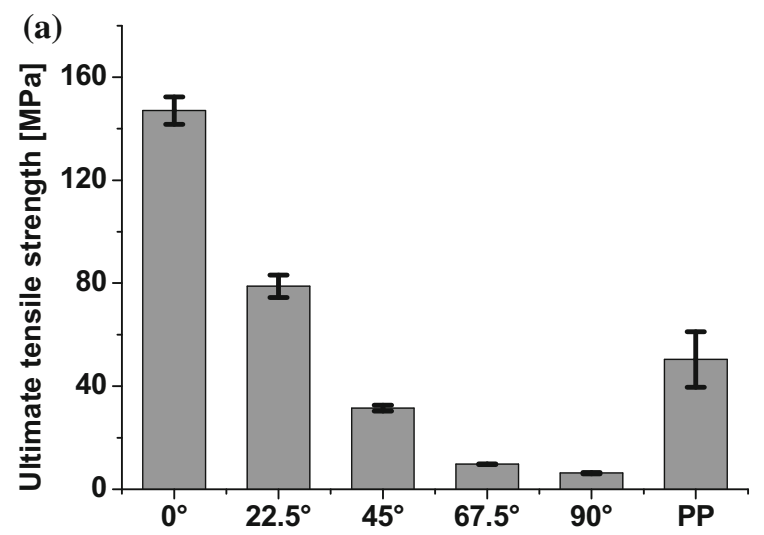

to $\pm 22.5^{\circ}$ a decrease of the UTS of $46 \%$ was observed. This shows the importance of the arrangement of the reinforcing fibres according to the load requirements. Small changes in the fibre orientation angle can induce substantial weakening of the material in the specific test directions. The UTS of the composites with $\pm 45^{\circ}$ fibre orientation angle is already considerable lower than the value of the used matrix material. This trend is still continuing for higher fibre orientation angles, the values for composites with $\pm 67.5^{\circ}$ and $90^{\circ}$ fibre orientation are in the range of $10 \%$ of the matrix value. This demonstrates the unfavourable anisotropic behaviour of fibre reinforced composites. Although considerable improvement of the mechanical properties along the fibre direction these values can be worse than that of the pure matrix material in other directions. Optical micrographs of broken Composites (after the tensile testing experiments) are shown in Fig. 3. The optical micrographs show that the fracture edge is preferred oriented along the direction of the reinforcing fibres, except for the composite with a fibre orientation angle of $0^{\circ}$.

A similar trend was observed for the E-modulus (Fig. 2b). At the beginning the E-modulus decreases quickly with increasing fibre orientation angle, but remains then more or less constant for fibre orientation angles larger than $67.5^{\circ}$. Composites with fibre orientation angles larger than $45^{\circ}$ are less stiff than the used PP matrix. The calculated volume fraction of voids in the composites is about 0.32 , therefore the volume fraction of the PP is only 0.49 . The volume fraction of voids $\left(V_{V}\right)$, PP matrix $\left(V_{m}\right)$ and fibres $\left(V_{f}\right)$

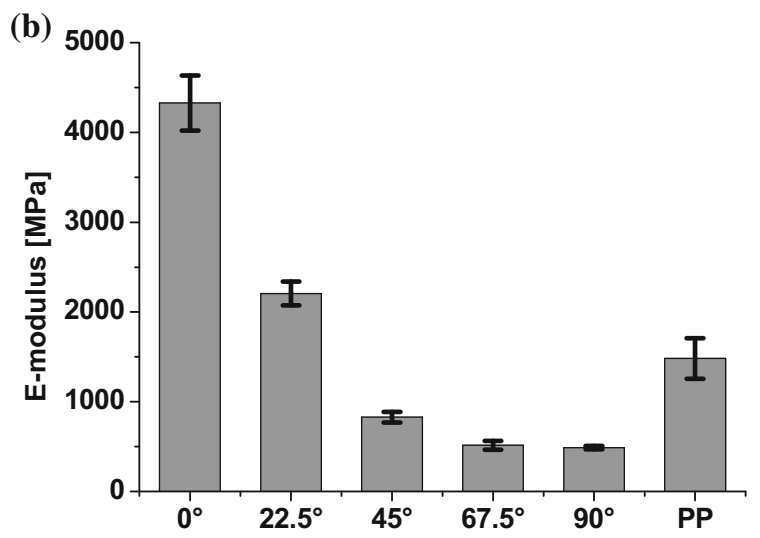

Fig. 2 Ultimate tensile strength and E-modulus of composites with different CLY fibre orientation and of the used polypropylene (PP) 


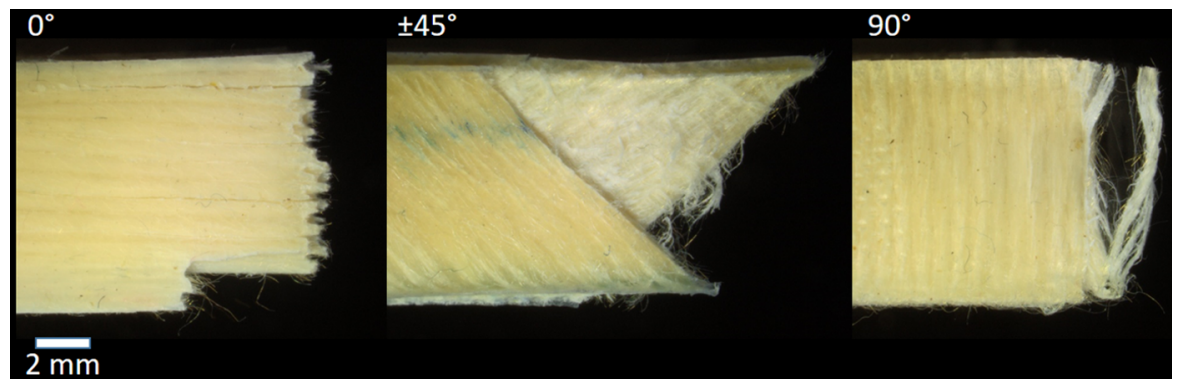

Fig. 3 Microscopy images of broken composites with a fibre orientation angle of $0^{\circ}, \pm 45^{\circ}$ and $90^{\circ}$

can be calculated from the density of composite $\left(\rho_{c}\right)$, PP matrix $\left(\rho_{m}\right)$ and CLY $\left(\rho_{f}\right)$, according to the following equations:

$\rho_{C}=V_{f} \rho_{f}+V_{m} \rho_{m}$

$V_{V}=1-V_{f}-V_{m}$

The composites with different fibre orientation have all the same mass to volume fraction and consequently the same volume fraction of voids. The size and distribution of voids can be observed with computer tomography (see Fig. 4). The E-modulus of composites with $\pm 67.5^{\circ}$ and $90^{\circ}$ fibre orientation is significant smaller than the half of the E-modulus value of the PP. In these cases the CLY fibres not only show no reinforcing effect, but even further lower the stiffness of the material. By fibre orientation angle $>$ $45^{\circ}$, delamination effect between fibres and matrix obviously plays the most important role by tensile testing and leads to the very low UTS and E-modulus.

In Fig. 5 the different values of elongation at ultimate tensile strength for the different composites are shown. In all cases the elongation is smaller than that of the pure matrix material, whereby the elongation has a maximum for a fibre orientation angle

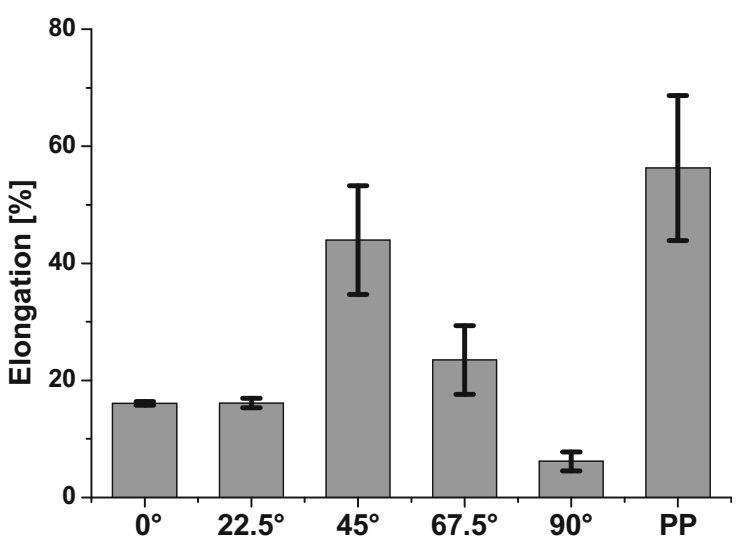

Fig. 5 Elongation of the different composites and polypropylene

of $\pm 45^{\circ}$. In principle, the elongation decreases when the stiffness of a material is increased by adding reinforcing fibres. A higher E-modulus means a stiffer, often also a more brittle material and so it is less deformable which breaks at low strain. Conversely, an elastic material has a lower E-modulus and so it is less brittle and breaks at higher deformation. Between the fibre orientation angles of 0 to $\pm 45^{\circ}$ the composites become softer, so that the materials are easier to

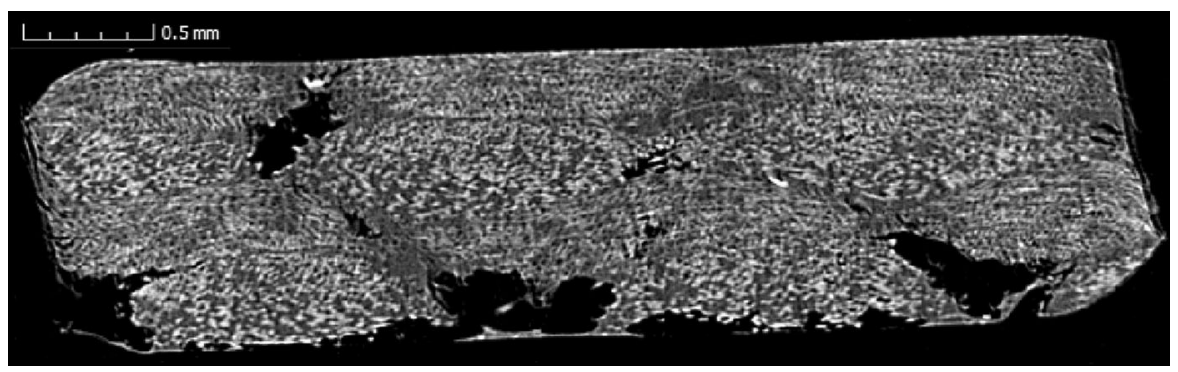

Fig. 4 Computer tomography image of the cross-section of a composite with $\pm 45^{\circ}$ fibre orientation. The CLY fibres are white, the PP is grey and the voids are shown as black structure in the image 
deform and so the elongation becomes larger. For fibre orientation angles larger than $\pm 45^{\circ}$ the elongation of the composite decreases. During tensile test, two opposite phenomena take place, namely reinforcement by CLY fibres and debonding of the fibres and the matrix. As can be seen in Fig. 2 the reinforcement effect decreases with increasing orientation angle as both UTS and E-modulus decrease. At the same time the elongation at UTS increases with orientation angle up to $45^{\circ}$ due to the less reinforcement effect of the fibres and hence, stronger contribution of PP matrix. As the orientation angle exceeds $45^{\circ}$, the delamination becomes dominant and lead to further decreased UTS and E-modulus, but also significant lower elongation at UTS, compared to composites with $45^{\circ}$ fibre orientation. The E-modulus of composites can be described theoretically by the so-called rule of mixture, which is the most simplified micromechanical model to predict tensile modulus. In the conventional rule of mixture a unidirectional fibre orientation is assumed. This model assumes a perfect adhesion between matrix and reinforcing fibres. Furthermore the assumption is made that all fibres are homogeneous with the same mechanical properties and regularly distributed in the matrix without the formation of agglomerates. The influence and volume fraction of voids in the composites are normally excluded in this model. The basic assumption of the rule of mixture model is that the matrix and fibres undergo the same strain under the influence of a load along the fibre direction. The rule of mixture formula for unidirectional continuous fibres aligned with the stress is (Virk et al. 2012):

$E_{C}=V_{f} E_{f}+V_{m} E_{m}$

$E_{C}$ is the composite E-modulus along the fibre direction, $E_{f}$ and $E_{m}$ are the E-modulus of the fibres and matrix, respectively. $V_{f}$ and $V_{m}$ are the fibre and matrix volume fraction. With the rule of mixture model it is possible to study the composite modulus with different fibre and matrix volume fraction. An advancement of this model is the modified rule of mixture, according to Virk et al. (2012) and Cullen et al. (2013):

$\mathrm{E}_{\mathrm{C}}=\kappa \eta_{\mathrm{d}} \eta_{1} \eta_{0} \mathrm{~V}_{\mathrm{f}} \mathrm{E}_{\mathrm{f}}+\mathrm{V}_{\mathrm{m}} \mathrm{E}_{\mathrm{m}}$

In this formula the contribution of the reinforcing fibres are modified by the four parameters $\kappa, \eta_{d}, \eta_{l}$ and $\eta_{0} . \kappa$ is the fibre area correction factor for non-circular fibres. The parameter $\eta_{d}$ is the fibre diameter distribution factor, which considered a dependence of the modulus on fibre diameter. The parameter $\eta_{l}$ is the fibre length distribution factor, which takes into account the load transmission between fibre and matrix as a function of the fibre length. The Emodulus of the composite is strongly influenced by the fibre orientation with respect to the direction of the applied load. This influence can be quantified by the parameter $\eta_{0}$ (Krenchel 1964):

$\eta_{0}=\sum_{n} a_{n} \cos ^{4} \theta_{n}$

$a_{n}$ is the proportion of fibres, which are oriented in an angle $\theta_{n}$ with respect to the direction of the applied load. In Fig. 6 the experimental and theoretical determined E-modulus as a function of the CLY fibre orientation angle is shown. For the simplified calculations a value of one was used for $\kappa, \eta_{d}$ and $\eta_{l}$. This can be justified by the fact, that the CLY fibres are nearly continuous with a staple length between 105 and $120 \mathrm{~mm}$ and with a diameter of approximately $17 \mu \mathrm{m}$, i.e. with very high aspect ratio. It is assumed that the E-modulus of the lyocell fibre is $20 \mathrm{GPa}$, based on the average of different values, published in the literature (Woodings 2001). The E-modulus of the used PP was determined in a separate tensile test series and has a value of $1.48 \mathrm{GPa}$. The weight ratio of PP and CLY in the composite is 62:38. Account has been taken that the volume fraction of voids in the

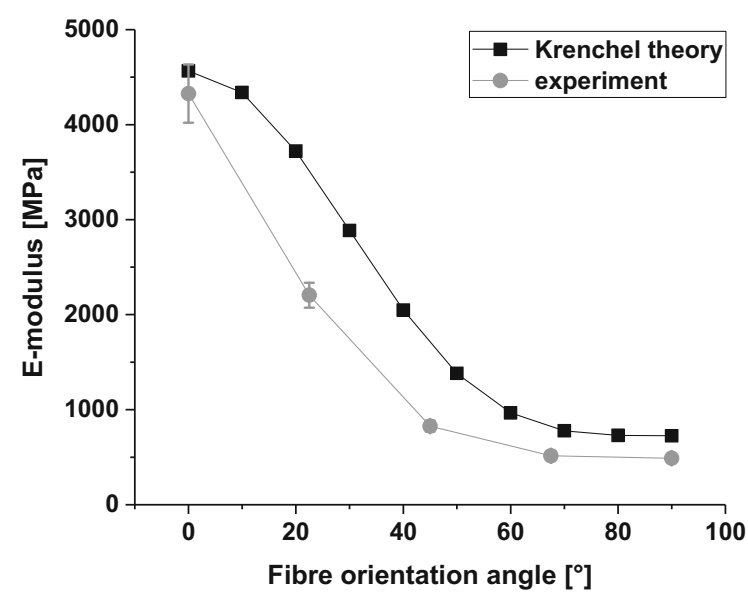

Fig. 6 Comparison of the experimental determined and calculated E-modulus by the modified rule of mixture, according to Virk and Krenchel 
composites was approximately 0.32 . Based on these values the E-modulus is calculated as a function of CLY fibre orientation and depicted in Fig. 6. It can be observed that the experimental values are smaller than the theoretical ones over the whole range of fibre orientation. The model is based on the assumption, that a perfect bonding between reinforcing fibres and the matrix is given. The deviation of the experimental data can be explained by the fact, that no coupling agent is used in this study. Although the used composites show excellent improved mechanical properties compared to pure matrix material, the influence of maleated PP will be studied in a future work.

Nevertheless the comparison between theoretical model and experimental data demonstrates the very high potential of the intermingled hybrid yarn concept for fibre reinforcement composites. For a fibre orientation angle of $90^{\circ}$ the term $\cos ^{4} \theta$ is zero, which means, that there is no contribution of the CLY fibres to the composite stiffness. Interestingly, the composite stiffness is smaller than the expected value. Obviously, the reinforcing fibres in the $90^{\circ}$ orientation additionally weaken the stiffness of the composite, which can be explained by the easy debonding of fibres and matrix.

The moisture sorption of PP-CLY composites was analysed in a previous paper (Cordin and Bechtold 2017). Cellulose containing composites can absorb considerable quantities of water, which influences the mechanical properties of the composites. In Fig. 7 the absorbed water content of the composites is shown as a

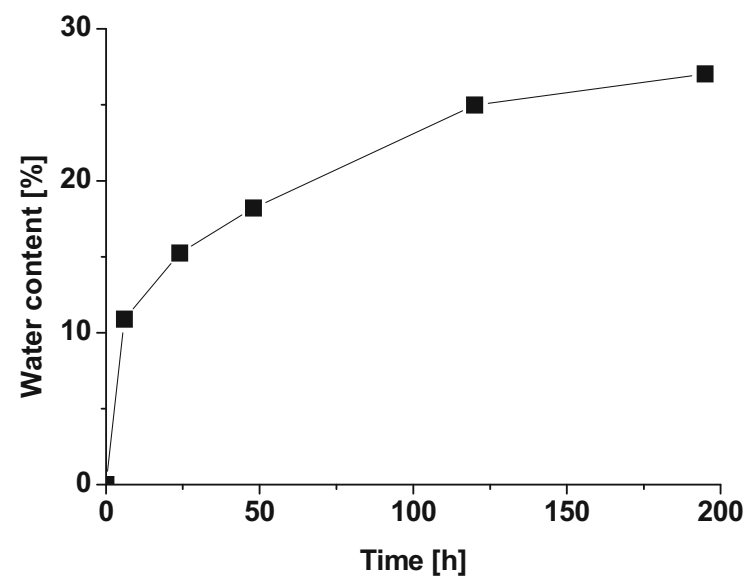

Fig. 7 Water content of the composites for different storage times in water function of time. The absorption occurred by direct contact of the composite with water.

It was found that water was sorbed very quickly at the beginning, then the sorption rate decreased with the continuation of the experiment. In Table 1 the water content of the hybrid yarn composites (62 wt $\%$ $\mathrm{PP}$, which corresponds to a volume fraction of 0.49 ) is compared with the values of fibre sliver composites with varying PP content. The preparation and mechanical properties of these fibre sliver composites (30-50 wt\% PP) were described in a previous paper (Cordin et al. 2017). One main difference between the new and previous prepared composites is the density and volume fraction of voids. Obviously a higher share of voids increases the sorption rate and content of water (Costa et al. 2007). In principle a higher proportion of PP means a better isolation of the hydrophilic fibres from water. The water content of the new prepared composites with a PP content of $62 \%$ reaches approximately an equilibrium state after a storage time of $195 \mathrm{~h}$ in water. These water saturated composites were used to perform tensile test and dynamic mechanical thermal analysis (DMTA) experiments.

The absorption of water mainly into the CLY part can induce weaking of the fibre-matrix interface, resulting in poor stress transfer from the matrix into the fibre. In principle, four different mechanisms for the water diffusion into the composite are known. There are micro gaps between the polymer chains, which allow the water to diffuse into the composite. Moreover there are gaps in the interface between fibres and polymer matrix, which are the root cause for capillary transport of water. This formation of gaps is especially pronounced for composites, which consist of components with different polarity, like cellulose type fibres and polypropylene matrix. Moreover water also induces swelling of the CLY fibres, which cause

Table 1 Comparison of the water content of fibre sliver composites (data from literature, Cordin and Bechtold 2017) and hybrid yarn composites (62 wt\% PP, which corresponds to a volume fraction of 0.49$)$. *...extrapolated values from data plotted in Fig. 7 for 19.5 and $87.5 \mathrm{~h}$

\begin{tabular}{lllll}
\hline PP content $(w t \%)$ & 30 & 40 & 50 & 62 \\
\hline $\mathrm{H}_{2} \mathrm{O}$ sorption after $19.5 \mathrm{~h} \mathrm{(wt \% )}$ & 44.9 & 29.4 & 10.0 & $14.2^{*}$ \\
$\mathrm{H}_{2} \mathrm{O}$ sorption after $87.5 \mathrm{~h} \mathrm{(wt \% )}$ & 46.9 & 35.0 & 19.0 & $21.4^{*}$
\end{tabular}


the formation of additional microcracks and increases the moisture sorption capacity of the composite. Besides a flow of water through the voids is possible.

All these different mechanisms in water sorption influence the mechanical properties of the composite. In Fig. 8 the stress-strain relation of dry and wet composites is compared. In Fig. 9a the ultimate tensile strength of dry and wet composites for fibre orientation angles of $0^{\circ}, \pm 45^{\circ}$ and $90^{\circ}$ are shown. The UTS of composites with $0^{\circ}$ fibre orientation decreased by $25 \%$ under the influence of water. For fibre orientation angle equal to or larger than $45^{\circ}$, the ultimate tensile strength of the composite is more or less the same for the dry and wet state. This supports the findings from the modified rule of mixture analysis, that there are no or little reinforcing effects of CLY fibres with a fibre orientation angle equal to or larger than $45^{\circ}$. As the fibres do not influence the strength of the composites in these cases, it does not matter if they are wet or not. A similar behaviour is also observed by the E-modulus of composites with different fibre orientations, which is shown in Fig. 9b. It is known that the E-modulus ratio between dry and wet CLY fibres is approximately 4 (Woodings 2001) and consequently the theoretical E-modulus ratio for a $0^{\circ}$-composite is approximately 3 . The stiffness reduction of composites with $0^{\circ}$ fibre orientation by water can be described by a factor of approximately 2.5 , which indicates that the CLY fibres in the composites are nearly saturated with water. The good accessibility of water into the composite can be explained by the relative high volume fraction of voids. The large water capacity of the fibres in the

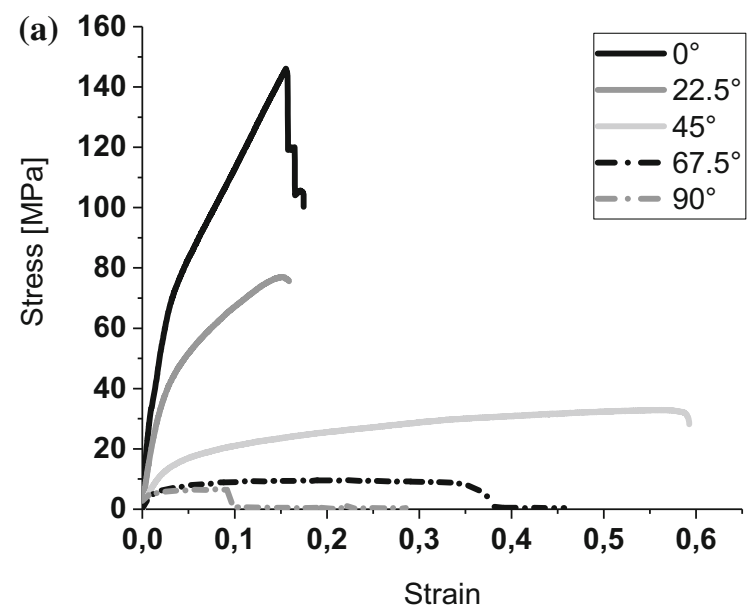

Fig. 8 Stress-strain relation for dry (a) and wet (b) composites composites indicates that the fibres are not surrounded by a closed layer of PP. For a fibre orientation angle equal to or larger than $45^{\circ}$, the E-modulus of the composite is more or less the same for the dry and wet state. This supports again the findings from the application of the modified rule of mixture. In case of large fibre orientation angles, the composite stiffness is contributed almost completely from the matrix PP. PP is a hydrophobic material and so its stiffness is not influenced by water, which explains the small E-modulus difference between dry and wet composites for large fibre orientation angles.

Water has also an influence on the elongation at ultimate tensile strength of PP-CLY composites. The change of the elongation between the dry and wet state depends on the fibre orientation in the analysed composite. In Fig. 10 the fibre orientation dependency of the elongation in the dry and wet state is shown. Obviously the percentage change increases with increasing fibre orientation angle, having a maximum at $45^{\circ}$, followed by a decrease of the percentage change of elongation with further increase of the fibre orientation angle.

The composites were also characterised by dynamic mechanical thermal analysis (DMTA). In these experiments the torque value was determined, which was necessary to twist the composite, whereby the rotation axis is parallel to the direction, in which the tensile force was applied in the tensile test experiment. From the torque value, the composite dimensions and clamping length it is possible to determine the storage and loss modulus. These values

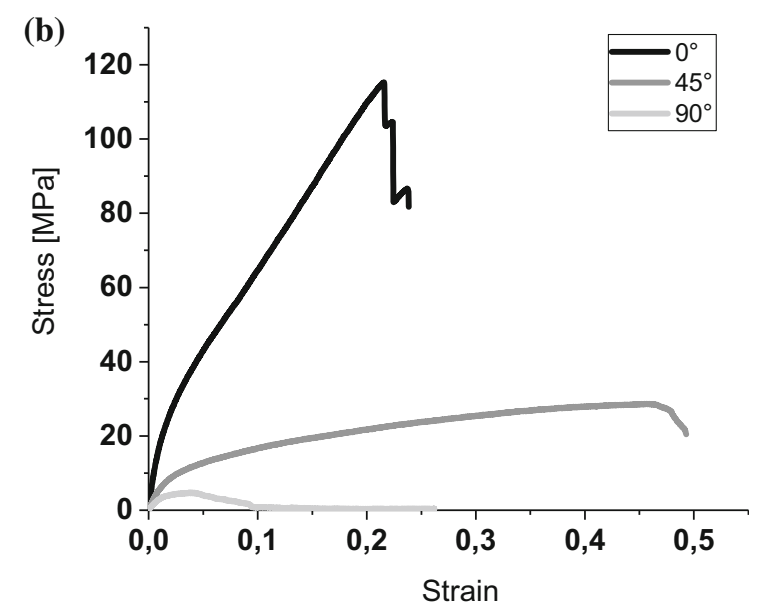



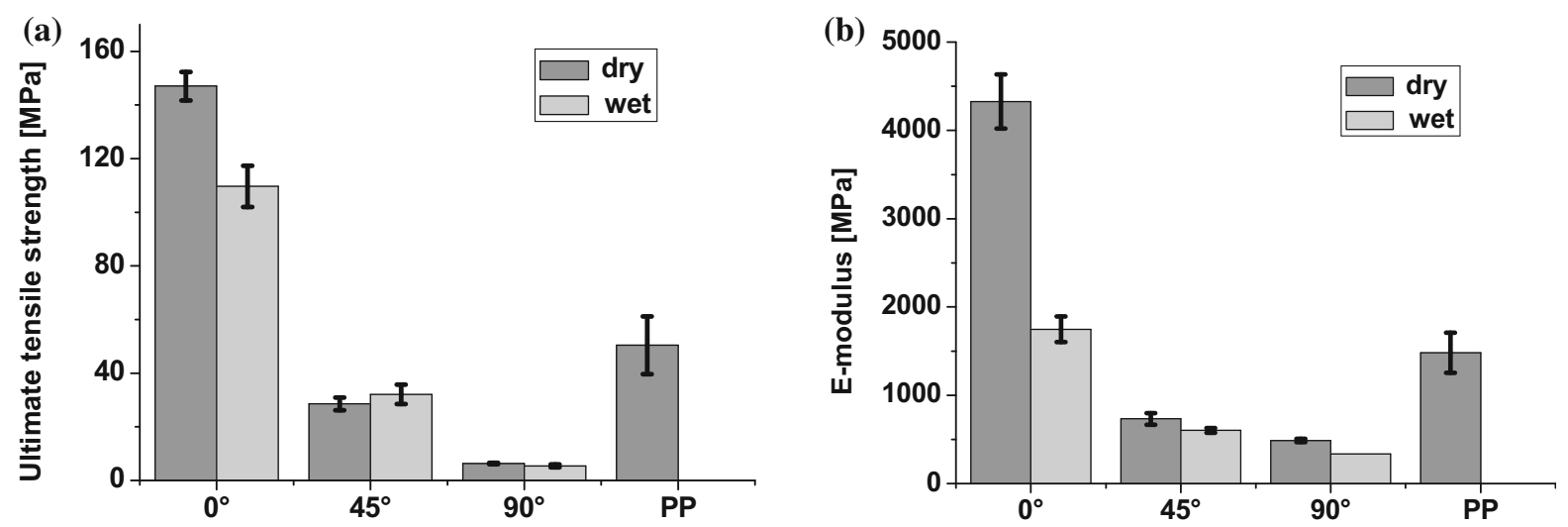

Fig. 9 UTS (a) and E-modulus (b) for different composites in the dry and wet state

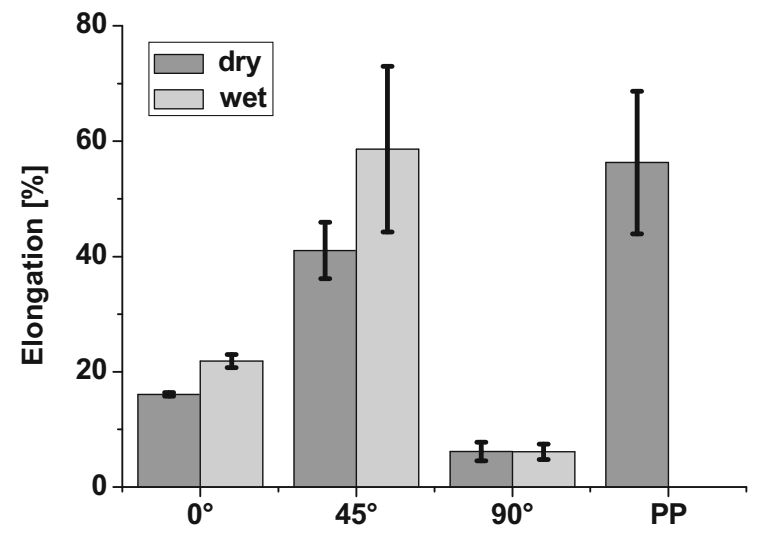

Fig. 10 A comparison of the elongations at ultimate tensile strength of dry and wet composites

were determined as a function of temperature. In Fig. 11 a the storage modulus is shown for different

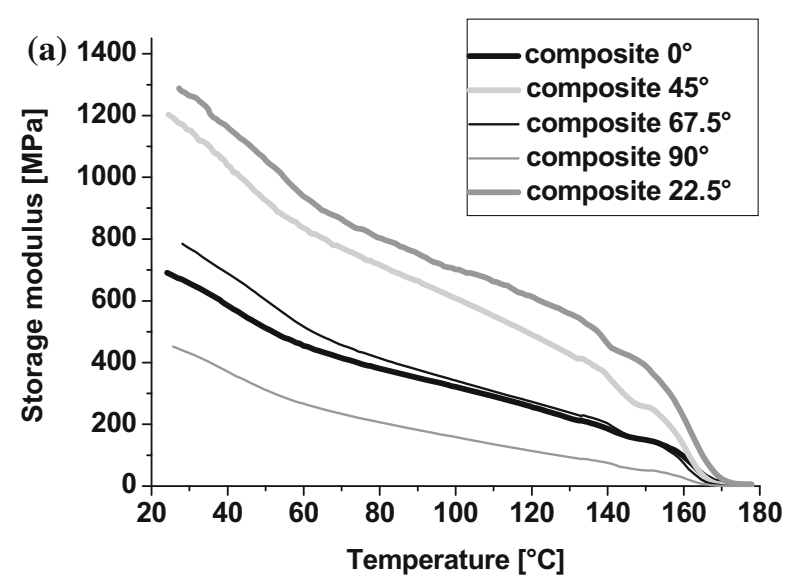

composites with different fibre orientations over a temperature range from 20 to $180{ }^{\circ} \mathrm{C}$. With increasing temperature the storage modulus decreases, which is mainly due to the stiffness reduction of the PP matrix. There are differences between the different composites with different fibre orientations. The best performance with respect to torsion is observed by the composite with $22.5^{\circ}$ CLY fibre orientation. Obviously the resistance against torsion is particularly well, when there is a reinforcement of the PP matrix in $\mathrm{x}$ - as well in y-direction. This also explains why the storage modulus is lowest for the composites with a fibre orientation angle of $0^{\circ}$ and $90^{\circ}$, because there is only a reinforcing effect in one direction.

As the melting temperature of PP is approximately $160{ }^{\circ} \mathrm{C}$, there is a large drop of the storage modulus near this temperature range and approaches zero by further increased temperatures. The loss modulus

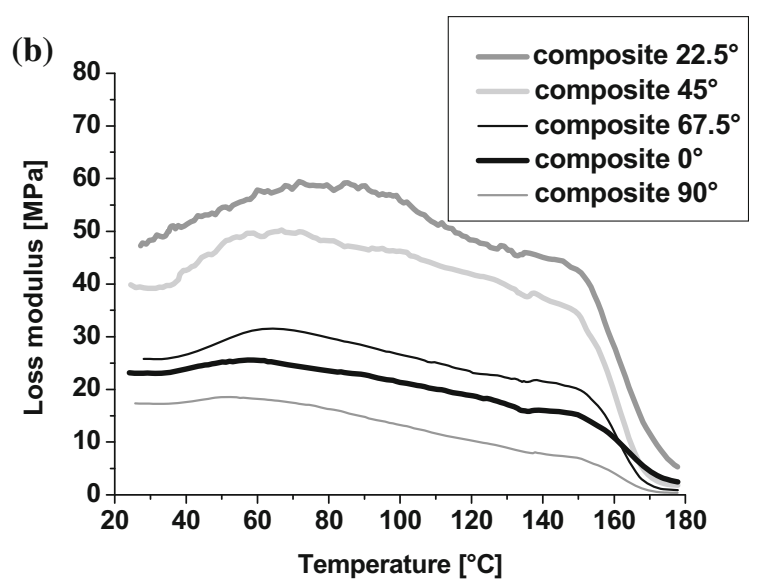

Fig. 11 Storage modulus (a) and loss modulus (b) of composites with different CLY fibre orientations 
describes the energy dissipation due to internal friction during the torsion of the composite and is depicted in Fig. $11 \mathrm{~b}$ for the different composites as a function of temperature. The loss modulus also decreases strongly near the melting temperature of PP. The influence of the fibre orientation on the loss modulus followed the same trend as in the case for the storage modulus. In Fig. 12a the storage modulus is shown for dry and wet composites at room temperature. The best performance can be observed for the composite with a fibre orientation of $45^{\circ}$. The contribution to the storage modulus is larger for fibres with an orientation of $0^{\circ}$ than for fibres with an orientation of $90^{\circ}$. Besides the storage modulus decreases under the influence of water is larger for the $0^{\circ}$ fibre orientation composite, because its contribution to the storage modulus is more significant than that of fibres with $90^{\circ}$ orientation. It therefore follows, that the highest storage modulus must be present in a composite with a fibre orientation angle smaller than $45^{\circ}$, which is indeed the case (see Fig. 11a). The loss modulus at room temperature is shown in Fig. 12b. There is nearly no change of the loss modulus under the influence of water, which indicates that the internal friction is limited more or less to the polypropylene.

The loss factor is the ratio between the storage modulus and loss modulus. The analysis of the loss factor is a sensitive method to detect phase transitions in a system. In Fig. 13 the loss factor is shown in the temperature interval from -20 to $+20{ }^{\circ} \mathrm{C}$. It is known that PP has a glass transition in this temperature range. The glass transition temperature can be determined from the position of the peak maximum of the loss factor. According to the loss factor, the glass

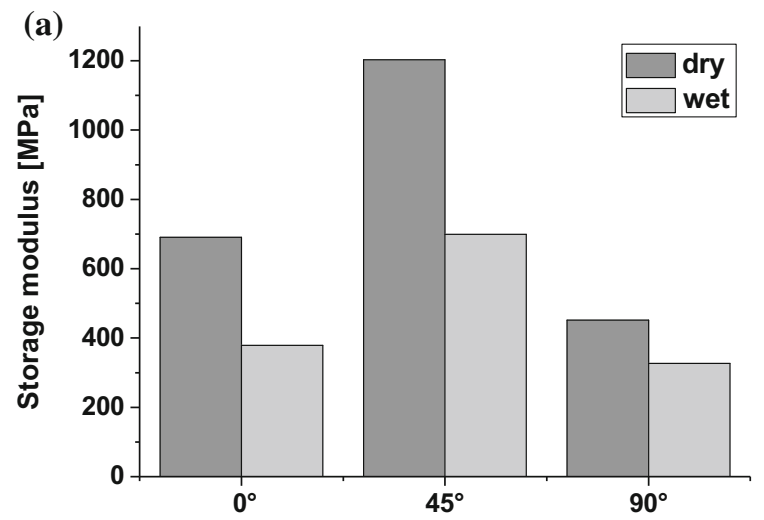

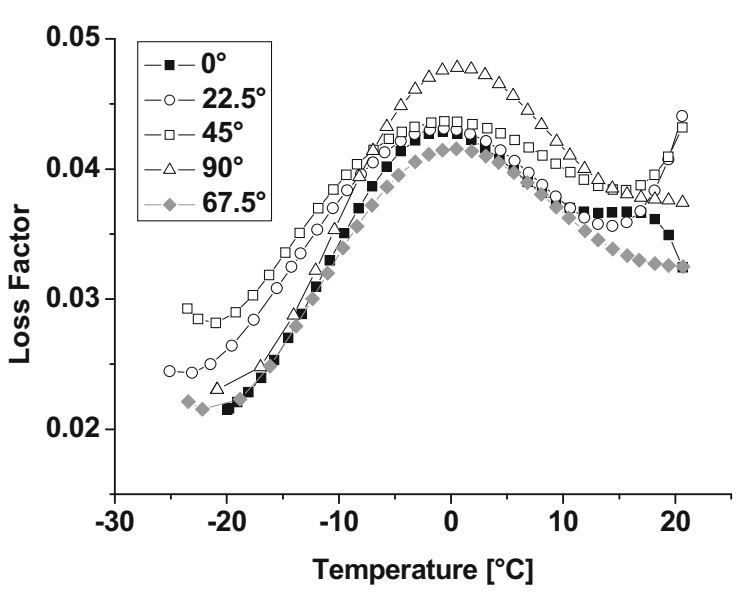

Fig. 13 Loss factor as a function of temperature and fibre orientation

transition of the different composites with different fibre orientations is around $0{ }^{\circ} \mathrm{C}$, which is in line with the glass transition of PP. This indicates that there is no influence of the fibre orientation on the phase transition of the PP matrix.

\section{Conclusion}

The aim of this work was the preparation and study of PP/CLY composites with different reinforcing fibre orientation, generated using special techniques of hybrid yarn, combined with defined laying process. The E-modulus depends strongly on the fibre orientation, which can be described theoretically by the modified rule of mixture. According to the theory the reinforcement by fibres is proportional to the fibre

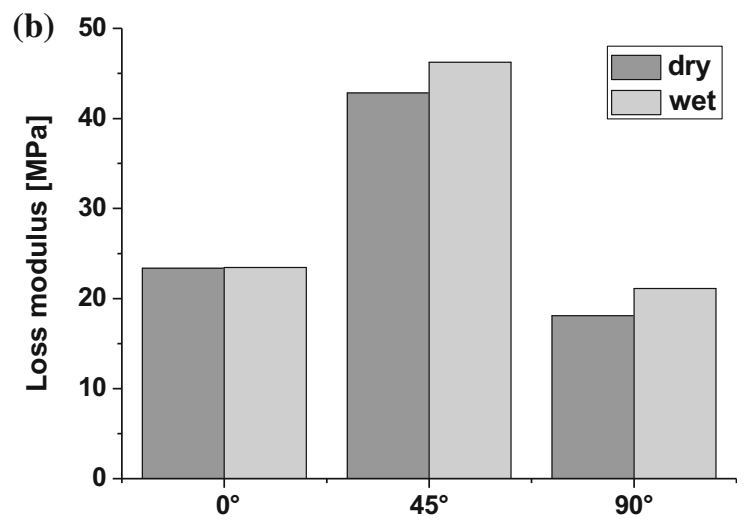

Fig. 12 Storage modulus (a) and loss modulus (b) of composites with different CLY fibre orientations at room temperature 
volume fraction and to $\cos ^{4} \theta$, whereby $\theta$ is the angle of the fibre orientation. This correlation was then confirmed experimentally. A similar trend was observed for the tensile strength as a function of the fibre orientation. The comparison between theoretical and experimental data provides information about the adhesion between fibres and matrix. For a fibre orientation angle of $90^{\circ}$ the term $\cos ^{4} \theta$ is zero, so there is no contribution to the stiffness by the fibres, they even reduce the stiffness compared to the pure matrix material due to decreased matrix volume fraction. This shows the importance of the analysis of the expected load for the design of composites. Here the modified rule of mixture is found to be a very suitable tool to predict the stiffness. The influence of moisture on the composite performance was also investigated. According to the literature the stiffness of wet CLY is $5.7 \mathrm{GPa}$, which results a stiffness of 1.8 GPa for a $0^{\circ}$-composite (Woodings 2001). In our study, the measured value of this composite is 1.7 GPa. This shows, that the influence of moisture can be described by the stiffness weakening of the lyocell fibres and the fibre-matrix adhesion is relatively unaffected. The moisture studies show the importance to protect this type of composite from moisture. Especially the formation of voids should be prevented, which increase the moisture sorption rate and capacity.

The composites were also studied by DMTA measurements. The resistance against torsion is approximately proportional to the storage modulus, if this value is much larger than the loss modulus. So the storage modulus is also suitable as a performance parameter to predict the composite suitability for special applications. Future work is planned to investigate the effect of coupling agent (e.g. PP-g-MAH modified fibres). Furthermore, we also plan to employ the special technical embroidery technique, such as tailored fibre placement (TFP) to generate composites with defined fibre orientation to prove our concept in a bigger scale.

Acknowledgments Open access funding provided by University of Innsbruck and Medical University of Innsbruck. The authors gratefully acknowledge financial support from the Austrian Federal Ministry of Transport, Innovation and Technology (BMVIT) to the Endowed Professorship Advanced Manufacturing FFG-846932. The authors wish to acknowledge Heinz Duelli for assistance with mechanical testing and Stefan Arzbacher for carrying out computer tomography measurements.

\section{Compliance with ethical standards}

Conflict of interest The authors declare that they have no conflict of interest.

Open Access This article is distributed under the terms of the Creative Commons Attribution 4.0 International License (http:// creativecommons.org/licenses/by/4.0/), which permits unrestricted use, distribution, and reproduction in any medium, provided you give appropriate credit to the original author(s) and the source, provide a link to the Creative Commons license, and indicate if changes were made.

\section{References}

Abdennadher A, Vincent M, Budtova T (2016) Rheological properties of molten flax- and Tencel-polypropylene composites: influence of fiber morphology and concentration. J Rheol 60:191-201. https://doi.org/10.1122/1. 4938224

Acha BA, Reboredo MM, Marcovich NE (2007) Creep and dynamic mechanical behavior of PP-jute composites: effect of the interfacial adhesion. Compos Part A Appl Sci Manuf 38:1507-1516. https://doi.org/10.1016/j. compositesa.2007.01.003

Adams RD, Bacon DGC (1973) Effect of fibre orientation and laminate geometry on the dynamic properties of CFRP. J Compos Mater 7:402-428. https://doi.org/10.1177/ 002199837300700401

Amash A, Zugenmaier P (1998) Study on cellulose and xylan filled polypropylene composites. Polym Bull 40:251-258. https://doi.org/10.1007/s002890050249

Amash A, Zugenmaier P (2000) Morphology and properties of isotropic and oriented samples of cellulose fibrepolypropylene composites. Polymer 41:1589-1596. https://doi.org/10.1016/S0032-3861(99)00273-6

Ashori A, Nourbakhsh A (2009) Polypropylene cellulose-based composites: the effect of bagasse reinforcement and polybutadiene isocyanate treatment on the mechanical properties. J Appl Polym Sci 111:1684-1689. https://doi. org/10.1002/app.29189

Bataille P, Ricard L, Sapieha S (1989) Effects of cellulose fibres in polypropylene composites. Polym Compos 10:103-108. https://doi.org/10.1002/pc.750100207

Belgacem MN, Bataille P, Sapieha S (2003) Effect of corona modification on the mechanical properties of polypropylene/cellulose composites. J Appl Polym Sci 53:379-385. https://doi.org/10.1002/app.1994.070530401

Bengtsson M, Le Baillif M, Oksman K (2007) Extrusion and mechanical properties of highly filled cellulose fibrepolypropylene composites. Compos Part A Appl Sci Manuf 38:1922-1931. https://doi.org/10.1016/j.compositesa. 2007.03.004

Bledzki AK, Gassan J (1999) Composites reinforced with cellulose based fibres. Prog Polym Sci 24:221-274. https:// doi.org/10.1016/S0079-6700(98)00018-5 
Borja Y, Rieß G, Lederer K (2005) Synthesis and characterization of polypropylene reinforced with cellulose I and II fibers. J Appl Polym Sci 101:364-369. https://doi.org/10. 1002/app.23847

Cordin M, Bechtold T (2017) Physical properties of lyocellreinforced polypropylene composites from intermingled fibre with varying fibre volume fractions. J Thermoplast Compos 31:1-13. https://doi.org/10.1177/ 0892705717734594

Cordin M, Griesser UJ, Bechtold T (2017) Analysis of moisture sorption in lyocell-polypropylene composites. Cellulose 24:1837-1847. https://doi.org/10.1007/s10570-017-12278

Costa ML, Rezende MC, De Almeida SFM (2007) Effect of void content on the moisture absorption in polymeric composites. Polym Plast Technol Eng 45:691-698. https:// doi.org/10.1080/03602550600609549

Cullen RK, Singh MM, Summerscales J (2013) Characterisation of natural fibre reinforcements and composites. J Compos 2013:1-4. https://doi.org/10.1155/2013/416501

Doan T, Gao S, Mäder E (2006) Jute/polypropylene composites I. Effect of matrix modification. Compos Sci Technol 66:952-963. https://doi.org/10.1016/j.compscitech.2005. 08.009

Doan T, Brodowsky H, Mäder E (2007) Jute fibre/polypropylene composites II. Thermal, hydrothermal and dynamic mechanical behaviour. Compos Sci Technol 67:2707-2714. https://doi.org/10.1016/j.compscitech. 2007.02 .011

Espert A, Vilaplana F, Karlsson S (2004) Comparison of water absorption in natural cellulosic fibres from wood and oneyear crops in polypropylene composites and its influence on their mechanical properties. Compos Part A Appl Sci Manuf 35:1267-1276. https://doi.org/10.1016/j. compositesa.2004.04.004

Feldmann M (2016) The effects of the injection moulding temperature on the mechanical properties and morphology of polypropylene man-made cellulose fibre composites. Compos Part A Appl Sci Manuf 87:146-152. https://doi. org/10.1016/j.compositesa.2016.04.022

Ganster J, Fink H (2006) Novel cellulose fibre reinforced thermoplastic materials. Cellulose 13:271-280. https://doi.org/ 10.1007/s10570-005-9045-9

Ganster J, Fink HP, Pinnow M (2006) High-tenacity man-made cellulose fibre reinforced thermoplastics: injection moulding compounds with polypropylene and alternative matrices. Compos Part A Appl Sci Manuf 37:1796-1804. https://doi.org/10.1016/j.compositesa.2005.09.005

Ganster J, Fink HP, Uihlein K et al (2008) Cellulose man-made fibre reinforced polypropylene: correlations between fibre and composite properties. Cellulose 15:561-569. https:// doi.org/10.1007/s10570-008-9204-X

Gassan J, Bledzki AK (1997) The influence of fibre-surface treatment on the mechanical properties of jutepolypropylene composites. Compos Part A Appl Sci Manuf 28:1001-1005. $835 X(97) 00042-0$

Gray DG (2008) Transcrystallization of polypropylene at cellulose nanocrystal surfaces. Cellulose 15:297-301. https:// doi.org/10.1007/s10570-007-9176-2
Huque QMI, Islam R, Islam MM et al (2012) Preparation of Rayon fiber-reinforced polypropylene composites by extrusion techniques. Polym Plast Technol 51:116-121. https://doi.org/10.1080/03602559.2011.618164

Hussain MR, Islam MA, Vuurea AV, Verpoest I (2013) Effect of fiber orientation on the tensile properties of jute epoxy laminated composite. J Sci Res 5:43-54. https://doi.org/10. 3329/jsr.v5i1.10519

Jackson PW, Cratchley D (1966) The effect of fibre orientation on the tensile strength of fibre-reinforced metals. J Mech Phys Solids 14:49-64. https://doi.org/10.1016/00225096(66)90019-6

Johnson RJ, Zink-Sharp A, Rennecker SH et al (2008) Mechanical properties of wetlaid lyocell and hybrid fiberreinforced composites with polypropylene. Compos Part A Appl Sci Manuf 39:470-477. https://doi.org/10.1016/j. compositesa.2007.12.007

Joly C, Gauthier R, Chabert B (1996) Physical chemistry of the interface in polypropylene/cellulose-fibre composites. Compos Sci Technol 56:761-765. https://doi.org/10.1016/ 0266-3538(96)00018-8

Joseph PV, Joseph K, Thomas S et al (2003) The thermal and crystallisation studies of short sisal fibre reinforced polypropylene composites. Compos Part A Appl Sci 34:253-266. https://doi.org/10.1016/S1359$835 \mathrm{X}(02) 00185-9$

Karmaker AC, Youngquist JA (1996) Injection molding of polypropylene reinforced with short jute fibres. J Appl Polym Sci 62:1147-1151. https://doi.org/10.1002/ (SICI)1097-4628(19961121)62:8\%3c1147:AID-APP2\% 3e3.0.CO;2-I

Khalid M, Ali S, Chuah AL et al (2006) Effect of MAPP as coupling agent on the mechanical properties of palm fibre empty fruit bunch and cellulose polypropylene biocomposites. Int J Eng Technol 3:79-84

Krenchel H (1964) Fibre reinforcement; theoretical and practical investigations of the elasticity and strength of fibrereinforced materials. Dissertation, Technical University of Denmark

Kuboki T (2014) Foaming behavior of cellulose fibre-reinforced polypropylene composites in extrusion. J Cell Plast 50:113-128. https://doi.org/10.1177/0021955X13504775

Madhuri KS, Rao HR, Reddy BCM (2017) Effect of fibre orientation and loading on the tensile properties of Hardwickia Binata fiber reinforced epoxy composites. Int J Pure Appl Math 117:57-61. https://doi.org/10.12732/ijpam. v117i10.11

Mirza FA, Afsar AM, Kim BS et al. (2009) Mechanical properties of lyocell fiber reinforced polypropylene composites. In: Proceedings of the international conference on mechanical engineering, vol 26-28, pp 1-6

Mirza F, Rasel S, Kim MS et al (2010) Lyocell fiber reinforced polypropylene composites: effect of matrix modification. Adv Mater Res 123-125:1159-1162. https://doi.org/10. 4028/www.scientific.net/AMR.123-125.1159

Niu P, Liu B, Wei X et al (2011) Study on mechanical properties and thermal stability of polypropylene/hemp fibre composites. J Reinf Plast Compos 30:36-44. https://doi.org/10. $1177 / 0731684410383067$

Paunikallio T, Kasanen J, Suvanto M et al (2003a) Influence of maleated polypropylene on mechanical properties of 
composite made of viscose fiber and polypropylene. J Appl Polym Sci 87:1895-1900. https://doi.org/10.1002/app. 11919

Paunikallio T, Suvanto M, Pakkanen TT (2003b) Composition, tensile properties, and dispersion of polypropylene composites reinforced with viscose fibers. J Appl Polym Sci 91:2676-2684. https://doi.org/10.1002/app.13450

Qiu W, Zhang F, Endo T et al (2003) Preparation and characteristics of composites of high-crystalline cellulose with polypropylene: effects of maleated polypropylene and cellulose content. J Appl Polym Sci 87:337-345. https:// doi.org/10.1002/app.11446

Qiu W, Zhang F, Endo T et al (2005) Effect of maleated polypropylene on the performance of polypropylene/cellulose composite. Polym Compos 4:448-453. https://doi. org/10.1002/pc.20119

Qiu W, Endo T, Hirotsu T (2006) Structure and properties of composites of highly crystalline cellulose with polypropylene: effects of polypropylene molecular weight. Eur Polym J 42:1059-1068. https://doi.org/10.1016/j. eurpolymj.2005.11.012

Quan H, Li Z, Yang M et al (2005) On transcrystallinity in semicrystalline polymer composites. Compos Sci Technol 65:999-1021. https://doi.org/10.1016/j.compscitech.2004. 11.015

Quillin DT, Caulfield DF and Koutsky JA (1992) Surface energy compatibilities of cellulose and polypropylene. In: Proceedings of Materials Research Society symposium, vol 266, pp 113-126. https://doi.org/10.1557/proc-266-113

Quillin DT, Caulfield DF, Koutsky JA (1993) Crystallinity in the polypropylene/cellulose system. I. Nucleation and crystalline morphology. J Appl Polym Sci 50:1187-1194. https://doi.org/10.1002/app.1993.070500709

Rahman R, Hasan M, Huque M et al (2010) Physico-mechanical properties of jute fibre reinforced polypropylene composites. J Reinf Plast Compos 29:445-455. https://doi. org/10.1177/0731684408098008

Shanks RA, Hodzic A, Wong S (2004) Thermoplastic biopolyester natural fibre composites. J Appl Polym Sci 91:2114-2121. https://doi.org/10.1002/app.13289

Shubhra QT, Alam A, Quaiyyum M (2011) Mechanical properties of polypropylene composites: a review. J Thermoplast Compos 26:362-391. https://doi.org/10.1177/ 0892705711428659

Spoljaric S, Genovese A, Shanks RA (2009) Polypropylenemicrocrystalline cellulose composites with enhanced compatibility and properties. Compos Part A Appl Sci Manuf 40:791-799. https://doi.org/10.1016/j.compositesa. 2009.03.011

Virk AS, Hall W, Summerscales J (2012) Modulus and strength prediction for natural fibre composites. Mater Sci Technol 28:864-871. https://doi.org/10.1179/1743284712Y. 0000000022

Wambua P, Ivens J, Verpoest I (2003) Natural fibres: can they replace glass in fibre reinforced plastics? Compos Sci Technol 63:1259-1264. https://doi.org/10.1016/S02663538(03)00096-4

Woodings C (2001) Regenerated cellulose fibres. Woodhead Publishing, Cambridge

Zarges JC, Minkley D, Feldmann M et al (2017) Fracture toughness of injection molded, man-made cellulose fiber reinforced polypropylene. Compos Part A Appl Sci Manuf 98:147-158. https://doi.org/10.1016/j.compositesa.2017. 03.022

Zugenmaier P (2006) Materials of cellulose derivatives and fibre-reinforced cellulose-polypropylene composites: characterization and application. Pure Appl Chem 78:1843-1855. https://doi.org/10.1351/pac200678101843 